\title{
Erratum
}

\section{A CASSCF and CCI study of the formation of the $\mathrm{Ni}_{2}\left(\mathrm{C}_{2} \mathrm{H}_{4}\right)$ complex}

\section{Per-Olof Widmark and Björn O. Roos}

Theor Chim Acta (1987) 71: 411-423

In the quoted paper, the binding energies between $\mathrm{Ni}_{2}$ and $\mathrm{C}_{2} \mathrm{H}_{4}$ were erroneously given as $24.6 \mathrm{kcal} / \mathrm{mol}$ at the CCI level of approximation and $28.1 \mathrm{kcal} / \mathrm{mol}$ with cluster corrections included. The error was due to an incorrect calculation of the CI wavefunction at the asymptotic limit. The correct binding energies are 15.8 and $20.9 \mathrm{kcal} / \mathrm{mol}$ respectively.

The authors thank Dr. M. R. A. Blomberg for suggesting that the original results were in error. 